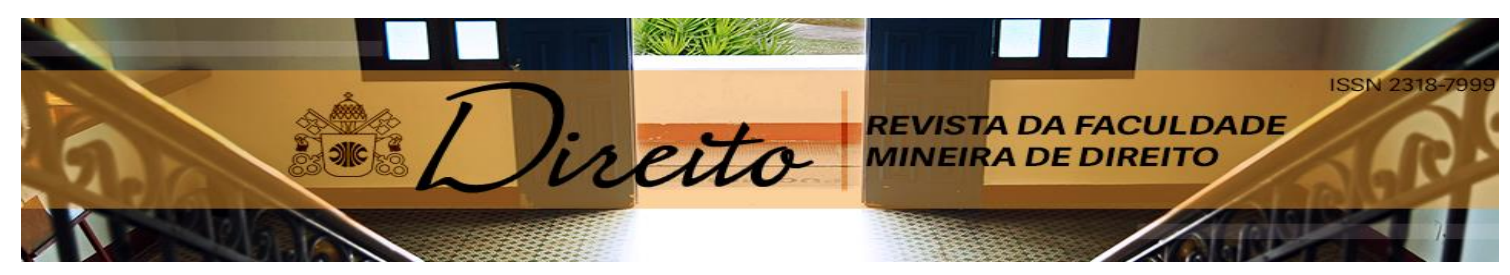

\title{
NEGOCIAÇÃO COLETIVA NO SERVIÇO PÚBLICO: OBSERVAÇÕES SOBRE A CONVENÇÃO № 151 DA OIT
}

\author{
COLLECTIVE BARGAINING IN THE PUBLIC SECTOR: OBSERVATIONS ON \\ CONVENTION № 151 OF ILO
}

Marco Aurélio Serau Junior ${ }^{1}$

\begin{abstract}
Resumo
O artigo discute as condições jurídicas para incorporação e implementação da Convenção oㅡ 151, da OIT, no ordenamento jurídico brasileiro, que cuida da negociação coletiva em relação aos servidores públicos. Aborda-se os limites legais para sua aplicação, em particular a reserva de lei e as restrições orçamentárias. Busca-se o exame dos mecanismos e procedimentos elaborados para sua regulamentação, questionando-se sua efetividade, sem perder de vista que a negociação coletiva se coloca como mecanismo que propicia grande nível de legitimidade às decisões tomadas, inclusive no âmbito do setor público.
\end{abstract}

Palavras-Chave: Direito. Trabalho. Internacional. OIT. Negociação coletiva. Estado.

\begin{abstract}
The article discusses the legal conditions for incorporation and implementation of Convention $\mathrm{n}^{\circ}$ 151 , of ILO, in the Brazilian legal system, which takes care of collective bargaining with respect to public servants. It approaches the legal limits to its application, in particular the law of reserves and budget constraints. Search is examining the elaborate mechanisms and procedures for its regulation, questioning whether its effectiveness, without losing sight of the collective bargaining arises as a mechanism that provides high level of legitimacy to the decisions taken, including within the public sector.
\end{abstract}

Key-words: Labor Law. International. ILO. Collective bargaining. Public administration

Artigo recebido em 03 de setembro de 2016 e aprovado em 11 de novembro de 2016.

${ }^{1}$ Doutor em Direitos Humanos pela Universidade de São Paulo, São Paulo, Brasil. 


\section{INTRODUÇÃO}

O artigo discute as condições jurídicas para incorporação e efetiva implementação da Convenção no 151 , da OIT, que trata da negociação coletiva em relação aos servidores públicos, no ordenamento jurídico brasileiro.

Busca-se o exame dos mecanismos e procedimentos elaborados para sua regulamentação, com vistas ao questionamento de sua efetividade, sem perder de vista que a negociação coletiva se coloca como mecanismo que propicia grande nível de legitimidade às decisões tomadas, inclusive no âmbito do setor público.

Quando às premissas metodológicas empregadas neste artigo, à míngua de específica base teórica sobre a negociação coletiva no setor público, utilizou-se o referencial teórico do Direito Coletivo do Trabalho, por analogia e de modo adaptado, vez que umbilicalmente vinculado às relações de trabalho desenvolvidas na iniciativa privada ${ }^{1}$.

A metodologia empregada na elaboração deste trabalho é eminentemente analíticobibliográfica, não tendo havido trabalho de campo, em que pese serem inafastáveis as impressões pessoais do autor do texto².

\section{AGENTES PÚBLICOS: OS TRABALHADORES DA ADMINISTRAÇÃO PÚBLICA.}

Antes de iniciar o enquadramento jurídico a respeito da negociação coletiva no âmbito do setor público, objeto próprio deste artigo, convém expor a delimitação das regras referentes ao pessoal que trabalha para o Estado.

A Administração Pública, para desempenhar suas funções, necessita do exercício de pessoas. Estes são os agentes públicos, subdivididos em três categorias: agentes políticos, servidores públicos e particulares em colaboração com a Administração.

Apenas os servidores públicos travam com o Estado uma relação de natureza profissional ou, em sentido amplo, uma relação de trabalho (NEIVA, 2012, p. 14-15). O conceito de servidor público corresponde, ademais, a um gênero, englobando três espécies definidas pela natureza da relação jurídica estabelecida com o ente público, que pode corresponder a vínculo de natureza institucional-estatutária, meramente empregatícia ou contratual-temporária, nos termos do art. 37, da Constituição Federal de 1988.

\footnotetext{
${ }^{1}$ Assumindo os riscos e padecendo, por consequência, da disfuncionalidade desse ramo do Direito (Direito Coletivo do Trabalho) como instrumento de regulação da experiência contemporânea dos conflitos entre capital e trabalho, conforme apontamento de FREITAS JR. (1989, p. 16).

${ }^{2}$ Embora o subjetivismo (puro e simples) seja algo a ser criticado no campo científico, não posso deixar de considerar, nesta pesquisa, a influência de minha condição pessoal, servidor público há quase duas décadas. Conforme GADAMER (2011, p. 410), é impossível seccionar o problema hermenêutico segundo "a subjetividade do intérprete e a objetividade de sentido que se trata de compreender", pois este "se aparta evidentemente de um saber puro, separado do ser". Ainda conforme este autor (GADAMER, 2011, p. 414): "o enorme alheamento que caracteriza a hermenêutica e a historiografia do século XIX, fruto do método objetivador da ciência moderna, mostrou ser a consequência de uma falsa objetivação", pois "uma hermenêutica das ciências do espírito não poderia extrair nenhum ensinamento dessa delimitação entre o saber ético e o saber nos moldes da matemática. Ao contrário, em oposição a essa ciência "teórica", as ciências do espírito fazem parte, estritamente, do saber ético. São "ciências morais". Seu objeto é o homem e o que este sabe de si mesmo".
} 
Os servidores públicos estatutários correspondem aos que estabelecem uma relação jurídica de natureza institucional-estatutária, que envolve a ocupação de unidade de poder denominada cargo público, o que ocorre através da prática de uma série de atos administrativos (nomeação, posse e exercício). Essa ocupação de cargo público pode ocorrer a título precário, no caso daqueles exclusivamente comissionados, ou através de provimento efetivo, que depende de aprovação em concurso público.

A relação contratual-empregatícia é estabelecida entre a Administração e aquele trabalhador do Estado que ostenta a condição de empregado público, sendo seu vínculo de trabalho regido pelo art. $3^{\circ}$, da Consolidação das Leis do Trabalho - obviamente com certas adaptações decorrentes do fato da relação jurídica se dar com a Administração Pública, como por exemplo a sujeição a sanções motivadas pela prática de atos de improbidade administrativa.

Os servidores temporários, nos termos do art. 37, IX, da Constituição Federal de 1988, são contratados apenas nas hipóteses de necessidade temporária e de excepcional interesse publico.

Conforme a sistemática estabelecida originalmente na Constituição Federal, antes da Emenda Constitucional no 19/98, o regime de emprego público somente poderia ser adotado no âmbito das empresas públicas e sociedades de economia mista, restando à Administração Direta, autarquias e fundações a adoção de relações estatutárias ou temporárias. Com a promulgação da Emenda Constitucional oㅜ 19/98, entretanto, admitiu-se o regime de emprego público em toda a Administração Pública, inclusive na Administração direta e indireta (autarquias).

Contudo, ao julgar a ADI 2.135 (MC/DF), o Supremo Tribunal Federal entendeu pela inconstitucionalidade da manifestação do poder constituinte derivado - com a promulgação da Emenda Constitucional no 19/98 - o que implicou no retorno ao modelo anterior, limitada a relação de emprego às empresas estatais e sociedades de economia mista. A modulação de efeitos dessa $A D I$, porém, determinou que os vínculos mantidos sob a égide da Emenda Constitucional no 19/98 deveriam ser preservados.

É importante registrar que o Direito do Trabalho strictu sensu (e todos seus aspectos protetivos decorrentes da presunção de desigualdade entre as partes) só se aplicará diretamente na esfera da Administração quando o vínculo estabelecido entre Estado e trabalhador for uma relação de emprego, correspondente ao emprego público (NEIVA, 2012, p. 21), e em alguma medida aos servidores temporários. As relações de trabalho dos servidores públicos estatutários são regidas sobretudo à luz dos ditames do Direito Administrativo, marcado pela verticalidade das relações e primazia do interesse público sobre o interesse particular.

Este quadro gera inegável tensão entre o campos do Direito do Trabalho e Direito Administrativo: enquanto este visa tutelar o interesse público e regular a atuação da Administração Pública, aquele se estrutura a partir do princípio da proteção, buscando compensar uma desigualdade existente no plano econômico por meio de um tratamento desigual no plano jurídico.

Esse choque hermenêutico fica mais nítido quando se considera que a fonte das obrigações da Administração consiste na lei (princípio da legalidade) e não a vontade do 
administrador e, no caso das vantagens salariais, subsiste também a lógica orçamentária (NEIVA, 2012, p. 29-32).

Entretanto, como assinala STOLL (2007, p. 45-46), não se pode negar a existência de uma conflituosidade específica da Administração Pública: "as relações entre servidores e Administração Pública possuem problemas específicos que envolvem questões políticas, sociais, econômicas e jurídicas diversas das existentes na iniciativa privada", ao que se agrega problemas aos existentes na iniciativa privada, como assédio moral, estabelecimento de metas excessivas de produtividade ou desigualdade de gênero.

O setor público também vêm se submetendo à situação de precariado, com privatizações de certos setores, adoção progressiva de contratos temporários (a exemplo da contratação massiva de professores temporários na rede pública) e/ou de estágio, no lugar de servidores efetivos, bem como a imposição de acúmulo indevido de funções e tarefas (STANDING, 2015, p. 85-89).

O tratamento destas questões, entretanto, na Adminstração Pública, deve observar as limitações impostas à Administração por regras e princípios constitucionais (Direito Administrativo).

Essa inequívoca tensão entre regras de Direito do Trabalho e postulados de Direito Administrativo que perpassa as discussões laborais/funcionais de servidores públicos, pode ser inserida no que SOUTO MAIOR (2011, p. 21-26) denominou de crise de identidade do Direito do Trabalho, ou no que vislumbrou FREITAS JR. (1999) como insuficiência regulatória das normas juslaboralistas em relação ao contemporâneo mercado de trabalho: há novos desafios ao Direito do Trabalho, novas relações de dependência econômica típicas da contemporaneidade, a exigir empenho intelectual no sentido de estender, com eficiência, também a estas, o princípio protetivo que norteia esse ramo do direito.

\section{FORMAS DE RESOLUÇÃO DOS CONFLITOS LABORAIS: PRIMAZIA DA NEGOCIAÇÃO COLETIVA.}

A resolução de conflitos, no campo do Direito do Trabalho, costuma ocorrer por três vias: autodefesa, autocomposição e heterocomposição (GARCIA, 2010, p. 1255).

A autodefesa consiste em uma situação em que as próprias partes procedem à defesa de seus interesses, de forma que uma delas impõe a sua vontade à outra, tal como a greve ou 0 lockout.

A autocomposição significa a solução do conflito pelas próprias partes, sem intervenção de terceiro, podendo ser classificada em unilateral, quando se verifica a renúncia de uma das partes à sua pretensão e/ou o reconhecimento da pretensão da parte contrária, ou bilateral, quando ocorrem concessões recíprocas, com natureza de transação.

No âmbito das relações de trabalho dá-se grande destaque à negociação coletiva como mecanismo de resolução dos conflitos coletivos, redundando em acordos coletivos ou convenções coletivas de trabalho.

A terceira modalidade de resolução de conflitos no âmbito do trabalho é a heterocomposição, assim definida a solução do conflito por terceiro, independentemente de aceitação das partes inseridas na controvérsia, a exemplo da arbitragem e da jurisdição. 
A negociação coletiva, em particular, pode ser considerada um dos pilares da sociedade democrática, visto que, realizada em bases justas (com lealdade, em observância ao princípio da boa-fé e do direito à informação), promove o diálogo social (GARCIA, 2010, p. 126).

Além das funções estritamente jurídicas, a negociação coletiva ainda exerce, como indicamos há pouco, função política, que reside em fomentar o diálogo na sociedade; função econômica, relacionada ao objetivo de distribuição de riquezas, e, por fim, função social, buscando harmonia no ambiente de trabalho e possibilitando o progresso social e maior desenvolvimento, quiçá promovendo a justiça social (GARCIA, 2010, p. 1263).

Aos servidores públicos civis é assegurado o direito à livre associação sindical (art. 37, VI, da Constituição Federal), direito este vedado ao militar (art. 142, § 3ํㅡㄴ inciso IV, do Texto Constitucional).

A negociação coletiva no âmbito do setor público, porém, sofre algumas restrições, a exemplo daquela retratada na Súmula 679 do Supremo Tribunal Federal: "A fixação de vencimentos dos servidores públicos não pode ser objeto de convenção coletiva".

No mesmo sentido a Orientação Jurisprudencial 05 , da Seção de Dissídios Coletivos (SDC), do TST: "Dissídio coletivo. Pessoa jurídica de direito público. Possibilidade jurídica. Cláusula de natureza social. Em face de pessoa jurídica de direito público que mantenha empregados, cabe dissídio coletivo exclusivamente para apreciação de cláusulas de natureza social. Inteligência da Convenção no 151 da Organização Internacional do Trabalho, ratificada pelo Decreto Legislativo n² 206/2010".

Antes de tratarmos especificamente da Convenção no 151 da OIT, abordaremos duas relevantes questões antecedentes: a regulação do direito de greve dos servidores públicos e o estágio da Convenção oํ 154 da OIT no ordenamento jurídico brasileiro.

\subsection{Breve nota sobre o direito de greve no serviço público.}

A Constituição Federal de 1988 (art. 37, VII) estabelece que a greve no serviço público será permitida nos termos de lei específica. Inova em relação ao regime constitucional anterior, em que a greve no setor público era expressamente vedada, inobstante a deflagração de inúmeras greves, mesmo sob a égide daquele outro regramento restritivo (MATTOS, 2010, p. 805).

Esse dispositivo constitucional é interpretado no sentido de que a Constituição Federal de 1988 revogou a proibição de greve no serviço público existente na Constituição anterior. Contudo, a norma seria de eficácia contida ou limitada, quer dizer, poderia ser limitada/condicionada pela mencionada lei específica, sobretudo no que concerne à continuidade das necessidades inadiáveis da comunidade (ROMITA, 2009, p. 371-372).

A greve dos servidores públicos (sob regime estatutário) é tratada diferentemente, do ponto de vista jurídico, da greve dos trabalhadores do setor privado, não sendo objeto do mesmo sistema de garantias, pois afetam mais a coletividade do que a própria Administração (ROMITA, 2009, p. 369-370). 
Assim, não se the aplica, primariamente, a Lei 7.783/89, destinada ao setor da iniciativa privada (MATTOS, 2010, p. 805). Além disso, alega-se que os servidores detêm vantagens que reforçam seu poder de barganha, como a estabilidade funcional e a garantia de pagamento de salários (ROMITA, 2009, p. 370).

Não se pode deixar de mencionar, em sentido contrário, que em muitos episódios de greves no setor público há casos de perseguição a lideranças e participantes do movimento grevista, bem como muitos episódios de "corte de ponto" e suspensão do pagamento de salários revertidos apenas no plano judicial.

O Supremo Tribunal Federal, no Mandado de Injunção no 708, julgado em 25.10.2007, tendo como Relator o Min. Gilmar Mendes, resolveu parcialmente a questão da ausência de regulamentação da greve no serviço público. Considerando a omissão legislativa existente na espécie, entendeu ser o caso de aplicar aos serviço público a Lei no $7.783 / 89$ enquanto persistisse referida omissão.

Reconheceu o Supremo Tribunal Federal o inegável conflito existente entre as necessidades mínimas de legislação para o exercício do direito de greve dos servidores públicos civis (CF, art. 9º, caput, c/c art. 37, VII), de um lado, e o direito a serviços públicos adequados e prestados de forma contínua a todos os cidadãos (CF, art. $9^{\circ}$, $\left.\S^{1} \stackrel{\circ}{ }\right)$, de outro.

Diante desses imperativos, definiu a Corte Constitucional que não se pode afastar, conforme as peculiaridades do caso concreto e mediante solicitação de entidade ou órgão legítimo, impor a observância de regime de greve mais severo, em razão de tratar-se de "serviços ou atividades essenciais", nos termos do regime fixado pelos arts. 9o a 11 da Lei o 7.783/1989.

Outrossim, pela complexidade e variedade dos serviços públicos e atividades estratégicas típicas do Estado, entendeu-se que há outros serviços públicos cuja essencialidade não está contemplada pelo rol dos arts. 9 a 11 da Lei no 7.783/89 - a enunciação do regime fixado naqueles artigos seria apenas exemplificativa (numerus apertus).

As autoridades judiciais competentes discutirão a abusividade da greve, decidindo acerca do mérito do pagamento, ou não, dos dias de paralisação em consonância com a excepcionalidade de que esse juízo se reveste. Nesse contexto, conforme o Supremo Tribunal Federal, nos termos do art. 70 da Lei ํo 7.783/89, a deflagração da greve corresponde à suspensão do contrato de trabalho, de modo que, como regra geral os salários dos dias de paralisação não deverão ser pagos, salvo no caso em que a greve tenha sido provocada justamente por atraso no pagamento aos servidores públicos civis, ou por outras situações excepcionais que justifiquem o afastamento da premissa da suspensão do contrato de trabalho (art. 7 으 da Lei no 7.783/1989, in fine).

Ademais, os tribunais competentes apreciarão e julgarão medidas cautelares relacionadas ao exercício do direito de greve dos servidores públicos civis, como o percentual mínimo de servidores públicos que deve continuar trabalhando durante o movimento paredista, ou mesmo a proibição de qualquer tipo de paralisação e os interditos possessórios para a desocupação de dependências dos órgãos públicos eventualmente tomados por grevistas.

Por último, o Excelso Pretório fixou o prazo de sessenta dias para que o Congresso Nacional legislasse sobre a matéria - descumprido até hoje. 
A perspectiva mais adequada, em nosso modesto ponto de vista, é aquela de evitar a greve no setor público, priorizando a busca de soluções negociadas (conciliação, mediação ou arbitragem), de sorte a atender aos interesses dos servidores públicos, da Administração e, muito mais, da própria coletividade. A greve restaria como forma de ultima ratio para exigência de direitos.

\subsection{Breve nota sobre a Convenção no 154 da OIT.}

A Convenção no 154 da OIT, sobre o incentivo à negociação coletiva, foi ratificada pelo Brasil, ademais incorporada ao ordenamento jurídico brasileiro pelo Decreto $n^{\circ} 1.256$, de 29.09.1994.

O art. 1, da referida Convenção, dispõe que se aplica a todos os ramos de atividade econômica e, mais precisamente $o$ art. 1ํa alínea ํㅡㄴ 3, estabelece seu cabimento ao setor público: "no que se refere à administração pública, a legislação ou a prática nacionais poderão fixar modalidades particulares de aplicação desta Convenção".

O exame da aplicação do estabelecido nessa Convenção à Administração Pública brasileira impõe seu desdobramento em dois segmentos, sejam eles relativos à aplicação do regime estatutário e do regime trabalhista.

No caso das entidades públicas sujeitas ao regime trabalhista (empresas públicas, sociedades de economia mista ou autarquias que explorem atividade econômica ${ }^{3}$ ) não paira dúvida acerca do cabimento da Convenção № 154 da OIT e da possibilidade de negociação coletiva pois, nos termos do art. 173, $\S 1^{\circ}$, inciso II, com a redação dada pela Emenda Constitucional no 19/98, essas atividades estão sujeitas ao regime jurídico próprio das empresas privadas, isto é, o regime trabalhista (ROMITA, 2009, p. 363-364).

É importante assinalar que o Supremo Tribunal Federal julgou inconstitucional o art. 240, alínea $d$, da Lei 8.112/90, que assegurava aos servidores estatutários federais o direito de negociação coletiva ${ }^{4}$. Essa orientação da Suprema Corte foi, ademais, seguida pelo Tribunal Superior do Trabalho, sob o argumento de que aos servidores estatutários não havia sido assegurado o reconhecimento das convenções e acordos coletivos de trabalho previstos no art. $7^{\circ}$, XXVI, da Constituição Federal, por falta de referência expressa ausente do art. 39 , § 2º , do mesmo diploma normativo.

A controvérsia acerca da aplicabilidade da Convenção no 154 da OIT ao setor público, entretanto, vê seu interesse prejudicado face a superveniência da ratificação da Convenção no 151, da OIT, pelo Brasil, da qual passamos a nos ocupar.

\footnotetext{
${ }^{3}$ A título de exemplo, podemos citar Caixa Econômica Federal, Banco do Brasil e Petrobrás, empresas onde ocorre negociação coletiva e em que as Convenções Coletivas dos respectivos setores são aplicáveis. 4 Julgou-se procedente a Ação Direta de Inconstitucionalidade $\mathrm{n}^{\circ}$ 492-1, Rel. Min. Carlos Velloso. Posteriormente, o art. 18, da Lei 9.527, de 10.12.1997, revogou expressamente as alíneas $d$ e $e$, do art. 240, da Lei 8.112/90.
} 


\section{A CONVENÇÃO № 151 DA OIT.}

A Conferência Geral da Organização Internacional do Trabalho, convocada pelo Conselho de Administração da Repartição Internacional do Trabalho, reunida em 27 de Junho de 1978 em Genebra (64. ${ }^{a}$ sessão), resolveu adotar a "Convenção relativa à proteção do direito de organização e aos processos de fixação das condições de trabalho na função pública”, de $n^{\circ}$ 151.

A adoção de uma Convenção sobre negociação coletiva específica para o setor público tomou em consideração alguns fatores, sobretudo que a Convenção Relativa ao Direito de Organização e Negociação Coletiva, de 1949, não abrange determinadas categorias de trabalhadores da função pública, bem como a considerável expansão das atividades do setor público em muitos países, ensejando a busca de caminhos para o estabelecimento de relações de trabalho sãs entre as autoridades públicas e as organizações de trabalhadores da função pública.

Conforme 0 art. 1 , da referida Convenção, esta se aplica "a todas as pessoas empregadas pelas autoridades públicas, na medida em que Ihes não sejam aplicáveis disposições mais favoráveis de outras convenções internacionais do trabalho".

Outrossim, a legislação nacional determinará "a medida em que as garantias previstas pela presente Convenção se aplicarão aos trabalhadores da função pública de nível superior, cujas funções são normalmente consideradas de formulação de políticas ou de direção ou aos trabalhadores da função pública cujas responsabilidades tenham um caráter altamente confidencial" (art. 1, item 2), bem como "a medida em que as garantias previstas pela presente Convenção se aplicarão às forças armadas e à polícia” (art. 1, item 3).

A Convenção adota uma posição bastante abrangente em relação ao que se entende por organização de trabalhadores do setor público: "Para os efeitos da presente Convenção, a expressão "organização de trabalhadores da função pública" designa toda a organização, qualquer que seja a sua composição, que tenha por fim promover e defender os interesses dos trabalhadores da função pública" (artigo 3).

Outrossim, repete aquilo que a OIT preconiza para a iniciativa privada quanto à importância do direito de livre associação sindical, indicando garantias para sua plena satisfação.

No que mais interessa ao objeto deste artigo, verifica-se que a Convenção № 151 traz importantes disposições em relação aos processos de fixação das condições de trabalho e resolução dos conflitos.

Seu artigo 7 promove que "devem ser tomadas medidas adequadas às condições nacionais para encorajar e promover o desenvolvimento e utilização dos mais amplos processos que permitam a negociação das condições de trabalho entre as autoridades públicas interessadas e as organizações de trabalhadores da função pública ou de qualquer outro 
processo que permita aos representantes dos trabalhadores da função pública participarem na fixação das referidas condições".

No mesmo sentido o teor do artigo 8, com a seguinte redação: "A resolução dos conflitos surgidos a propósito da fixação das condições de trabalho será procurada de maneira adequada às condições nacionais, através da negociação entre as partes interessadas ou por um processo que dê garantias de independência e imparcialidade, tal como a mediação, a conciliação ou a arbitragem, instituído de modo que inspire confiança às partes interessadas".

\section{INCORPORAÇÃO E REGULAMENTAÇÃO DA CONVENÇÃO № 151 DA OIT NO ORDENAMENTO JURÍDICO BRASILEIRO.}

O Decreto ํㅜ 7.944, de 06.03. 2013, promulgou no Brasil a Convenção ํㅜ 151 e a Recomendação no 159, ambas da Organização Internacional do Trabalho, sobre as Relações de Trabalho na Administração Pública, firmadas em 1978.

Outrossim, apresentou declaração interpretativa das expressões "pessoas empregadas pelas autoridades públicas" e "organizações de trabalhadores", abrangidas por aquela Convenção, nos seguintes termos (art. 1ํ, incisos I e II):

I - a expressão "pessoas empregadas pelas autoridades públicas", constante do item 1 do Artigo 1 da Convenção no 151, abrange tanto os empregados públicos, ingressos na Administração Pública mediante concurso público, regidos pela Consolidação das Leis do Trabalho CLT, aprovada pelo Decreto-Lei no 5.452, de 10 de maio de 1943, quanto os servidores públicos no plano federal, regidos pela Lei no 8.112, de 11 de dezembro de 1990, e os servidores públicos nos âmbitos estadual e municipal, regidos pela legislação específica de cada um desses entes federativos; $e$

II - consideram-se "organizações de trabalhadores" abrangidas pela Convenção apenas as organizações constituídas nos termos do art. $8^{\circ}$ da Constituição.

Nos termos do art. $2^{\circ}$, do Decreto $n^{\circ} 7.944 / 2013$, ficam sujeitos à aprovação do Congresso Nacional atos que possam resultar em revisão das referidas Convenção e Recomendação, bem como ajustes complementares que acarretem encargos ou compromissos gravosos ao patrimônio nacional, nos termos do art. 49, inciso I, da Constituição Federal.

Atualmente, tramita no Poder Legislativo o PLS no 287/2013, de Relatoria do Senador Paulo Paim (PT-RS), que visa regulamentar a Convenção no 151 da OIT. Tal projeto assegura o direito à livre associação de classe, a negociação coletiva e o direito de greve como direitos fundamentais indissociáveis do processo de democratização das relações de trabalho no âmbito da Administração Pública 5 .

\footnotetext{
${ }^{5}$ Conforme seus arts. $2^{\circ}$ e $3^{\circ}$ :
} 
Procurando dar efetividade à ideia de negociação coletiva no setor público estabelece prazo para que, apresentadas as reivindicações à Administração Pública, seja estabelecida a mesa de negociação. ${ }^{6}$

A título de garantia da segurança jurídica do objeto debatido na negociação coletiva, bem como sua efetiva força jurídica, o PLS 287/13 estabelece a necessidade de publicação dos termos da negociação no respectivo Diário Oficial, com detalhamento de seu conteúdo, e que os acordos firmados são bilaterais, comprometendo as partes para seu cumprimento. ${ }^{7}$ Esse dispositivo proposto é interessante, à medida que busca impedir "viradas de mesa", a exemplo de interromper-se greve em troca de certas promessas por parte do Estado, as quais são imediatamente descumpridas.

O PLS 287/13 avança positivamente em relação às disposições da Convenção no 151 da OIT e cria a figura dos observatórios das relações de trabalho no serviço público ${ }^{8}$.

As disposições do PLS 287/2013 respeitam o princípio da reserva legal e da legalidade orçamentária, mas trazem proposta mais incisiva, buscando dar mais efetividade à negociação coletiva e, nesse rumo, determina-se que a "autoridade competente terá até o dia 31 de agosto

\footnotetext{
"Art. $2^{\circ}$ Aos servidores e empregados públicos da administração pública direta, autárquica ou fundacional de qualquer dos Poderes da União, dos Estados, do Distrito Federal e dos Municípios, fica assegurado o direito à livre associação de classe, a negociação coletiva e o direito de greve por serem preceitos constitucionais indissociáveis do processo de democratização das relações de trabalho no âmbito da administração pública.

Art. $3^{\circ}$ A liberdade e a autonomia de organização de classe dos servidores e empregados públicos da administração pública direta, autárquica ou fundacional de qualquer dos Poderes da União, dos Estados, do Distrito Federal e dos Municípios, pressupõem o direito à negociação coletiva, inclusive como instrumento de solução de conflitos nas relações de trabalho".

O direito à livre associação sindical é tratado mais amiúde nos arts. $5^{\circ}$ a $8^{\circ}$, do PLS 287/2013.

${ }^{6}$ Eis o teor do art. 12 do referido projeto:

“Art. 12. Apresentada a pauta de reivindicações nos termos do $\S 4^{\circ}$ do art. 11, a administração pública adotará os seguintes procedimentos:

I - instalará mesa de negociação coletiva;

II - manifestar-se-á, no prazo de 60 (sessenta) dias contados do recebimento das reivindicações, acolhendoas, apresentando proposta conciliatória ou fundamentando a impossibilidade de seu atendimento.

Parágrafo único. O descumprimento do prazo estabelecido no inciso II deste artigo ou a apresentação de resposta desacompanhada de elementos aptos a sustentar as alegações apresentadas possibilita à administração pública e à entidade de classe representativa da categoria a escolha por até 60 (sessenta) dias de métodos alternativos de solução de conflitos através de mediação, conciliação ou arbitragem."

${ }^{7}$ Conforme seus artigos 13 e 14 :

"Art. 13. Os acordos oriundos da negociação coletiva serão registrados em instrumentos firmados pelas partes e publicados no Diário Oficial correspondente.

Parágrafo único. Dos instrumentos firmados pelas partes constarão, no mínimo, a abrangência, a aplicabilidade, os prazos e a vigência do quanto acordado.

Art. 14. Os acordos firmados são bilaterais, comprometendo as partes ao cumprimento das providências para sua efetivação e ao zelo para sua manutenção."

${ }^{8}$ Conforme disposição prevista em seu art. 22:

"Art. 22. Ficam instituídos os observatórios das relações de trabalho no serviço público, no âmbito dos Poderes da União, dos Estados, do Distrito Federal e dos Municípios, de caráter tripartite, com o objetivo de:

I - atuar como observador, instância consultiva e mediadora nos eventuais conflitos advindos das mesas de negociação coletiva;

II - avaliar projetos de autorregulamentação de greve a que se refere o parágrafo único do art. 18 desta Lei; III - desenvolver estudos e pesquisas na área das relações de trabalho no serviço público.

Parágrafo único. A composição do observatório das relações de trabalho no serviço público observará a relação de proporção entre seus membros, devendo a indicação da totalidade dos membros da sociedade civil organizada ser realizada pelas bancadas na proporção de 50\% (cinquenta por cento) para a bancada governamental e $50 \%$ (cinquenta por cento) para as entidades de classe".
} 
de cada ano para encaminhar projeto de lei ao Poder Legislativo, nos termos da Lei de Diretrizes Orçamentárias e Lei Orçamentária Anual, com efeitos financeiros a partir de janeiro do ano seguinte", constando desse projeto de lei "a abrangência, as condições, a aplicabilidade, os prazos e a vigência do acordado na negociação coletiva" (art. 25 do PLS 287/13).

O PLS no 287/2013 tramita em conjunto com o PLS no 710/2011, de relatoria do Senador Aloysio Nunes Ferreira (PSDB/SP), que, em verdade, busca regulamentar o direito de greve no serviço público e, incidentalmente, trata das negociações coletivas como mecanismo prévio à greve como forma de solução dos conflitos entre Administração e servidores públicos ${ }^{9}$.

Nesse sentido, o PLS no 710/2011 propõe que sejam instaurados os mecanismos consensuais de solução de conflitos quando houver assembleia geral dos movimentos de servidores donde se tire indicativo de greve, sendo observados os parâmetros adotados na Convenção oㅜ 151, do OIT, especialmente o emprego das técnicas de mediação, conciliação e arbitragem, inclusive com mesa emergencial de negociação ${ }^{10}$.

Um dos mecanismos de incentivo à negociação coletiva no âmbito do setor público adotado no PLS 710/2011 reside em considerar como ato de improbidade administrativa, no caso dos representantes do Estado, ou apenar com multa, no caso dos sindicatos dos servidores públicos, aqueles que frustrarem ou se recusarem à participação na negociação ${ }^{11}$.

\footnotetext{
${ }^{9}$ Nesse sentido, o art. $5^{\circ}$, do referido projeto:

"Art. $5^{\circ}$ As deliberações aprovadas em assembleia geral, com indicativo de greve, serão notificadas ao Poder Público para que se manifeste, no prazo de trinta dias, acolhendo as reivindicações, apresentando proposta conciliatória ou fundamentando a impossibilidade de seu atendimento."

${ }^{10}$ É o teor dos arts. $7^{\circ}$ e $8^{\circ}$, daquele projeto:

“Art. $7^{\circ}$. Após a notificação de que trata o art. $5^{\circ}$, o Poder Público instalará mesa emergencial de negociação coletiva, como espaço específico destinado ao tratamento das reivindicações dos servidores públicos.

$\S 1^{\circ}$ Havendo acordo integral, encerrar-se-á a negociação coletiva com a assinatura de termo de acordo pelos representantes do Poder Público e dos servidores.

$\S 2^{\circ}$ As cláusulas do termo de acordo abrangidas por reserva legal e por reserva de iniciativa serão encaminhadas ao titular da iniciativa da respectiva lei, para que as envie, na forma de projeto, ao Poder Legislativo, obedecidas as balizas orçamentárias e as de responsabilidade fiscal.

$\S 3^{\circ}$ Quando o titular da iniciativa legislativa de que trata o $\S 2^{\circ}$ deste artigo for o Chefe do Poder Executivo, o projeto de lei será encaminhado em regime de urgência constitucional ao Poder Legislativo.

$\S 4^{\circ}$ Havendo acordo parcial, a parte consensual seguirá o previsto nos $\S \S 1^{\circ}$ e $2^{\circ}$ deste artigo e a parte controversa será submetida, se for o caso, a processos alternativos de solução de conflitos de que trata o art. $8^{\circ}$ desta Lei, ou ao Poder Judiciário.

$\S 5^{\circ}$ Não havendo acordo, a matéria receberá o tratamento descrito na parte final do $\S 4^{\circ}$ deste artigo.

Art. $8^{\circ}$. Caso reste infrutífero o processo de negociação envolvendo os servidores e o Poder Público, a pauta de reivindicações poderá, caso haja consenso, ser submetida a métodos alternativos de solução de conflitos como mediação, conciliação ou arbitragem, instituídos de modo a garantir a independência e a imparcialidade da decisão e a inspirar confiança nas partes interessadas.

$\S 1^{\circ}$ Solucionado o conflito, será subscrito termo pelos representantes dos servidores e do Poder Público, ou será proferida sentença arbitral, observado o disposto nos $\S \S 1^{\circ}$ e $2^{\circ}$ do art. $7^{\circ}$ desta Lei.

$\S 2^{\circ}$ Havendo acordo parcial, a parte consensual seguirá o previsto nos $\S \S 1^{\circ}$ e $2^{\circ}$ do art. $7^{\circ}$ desta Lei e a parte controversa será submetida ao Poder Judiciário.

$\S 3^{\circ}$. Não havendo acordo, a matéria será submetida ao Poder Judiciário."

${ }^{11}$ É o teor do art. 30 do referido projeto, transcrito abaixo:

"Art. 30. Submetida a análise da greve ao Poder Judiciário, o juízo ou Tribunal da causa decidirá, inicialmente, sobre a eventual inexistência de efetivo interesse de uma das partes em implementar o processo de negociação coletiva de que trata esta Lei, após o que, o julgamento seguirá o disposto nesta Lei.

$\S 1^{\circ}$ Caso a não-implementação efetiva do processo de negociação coletiva seja imputada ao Poder Público, serão considerados atos de improbidade administrativa, previstos no art. 11, inciso II, da Lei n ${ }^{\circ} 8.429$, de 2
} 


\section{POSSIBILIDADE JURÍDICA DA RESOLUÇÃO DE CONFLITOS ENTRE SERVIDORES PÚBLICOS E ADMINISTRAÇÃO PÚBLICA PELA VIA NEGOCIADA.}

É corrente na doutrina que os servidores públicos se encontram em relação estatutária ou de sujeição especial em relação ao Estado, sendo inaplicável a esses o regime jurídico destinado aos trabalhadores da iniciativa privada. Porém, há algum avanço doutrinário reconhecendo certo vínculo "contratual" ou de sujeição entre ambos, no sentido de que o servidor público não possui apenas deveres para com o Estado, mas também direitos que devem ser respeitados, a despeito do intenso ius variandi que permite ao Estado modificar substancialmente as condições iniciais do pacto formado entre ambos (BOTASSI, 2006, p. 90).

Também digno de menção é o fenômeno da privatização ou laboralização do emprego público, que concerne na incorporação de Tratados Internacionais e promulgação de leis internas que conferem direitos sociais aos trabalhadores da esfera pública, como regulamentação do direito de greve, cobertura dos acidentes de trabalho, direito de associação sindical, dentre outras (BOTASSI, 2006, p. 93; STOLL, 2007, p. 46).

Paralelamente $a$ isso ocorre uma tendência ao emprego de critérios igualatórios entre Estado e indivíduo, os quais, mutatis mutandis, se mostram semelhantes aos utilizados no Direito do Trabalho para a relação empresário-operário, na medida em que tendem a compensar a desvantagem econômica e de poder em que se encontra a parte mais frágil da relação jurídica (BOTASSI, 2006, p. 109).

De certo modo, não há mesmo diferença substancial entre as relações laborais desenvolvidas no âmbito da iniciativa privada e as relações que ocorrem entre servidores públicos e Estado-Administração: em ambos os casos tem-se o labor físico ou intelectual exercido por uma pessoa física em troca de remuneração, com habitualidade, pessoalidade e subordinação ${ }^{12}$; muda apenas a figura do empregador, que, no caso dos servidores públicos é uma pessoa jurídica de Direito Público (BOTASSI, 2006, p. 92).

Além disso, "a relação mantida entre o Estado e seus trabalhadores (...) é permeada por conflitos decorrentes da dicotomia existente entre todo trabalhador em face do detentor dos meios econômicos e de produção, na busca de melhores condições de vida e de meios para o exercício do próprio trabalho" (STOLL, 2007, p. 70).

Nesse jaez, ROMITA (2009, p. 213-214) defende que os direitos fundamentais não valem apenas para os trabalhadores da iniciativa privada, mas a todos que exerçam atividade remunerada por conta de outrem de quem dependam do ponto de vista econômico. Substitui-se

de junho de 1992, os procedimentos comissivos ou omissivos do agente público designado para representar o Poder Público no processo de negociação coletiva de que trata esta Lei.

$\S 2^{\circ} \mathrm{Se}$ a responsabilidade pela não-implementação efetiva do processo de negociação coletiva recair sobre os representantes dos trabalhadores, será atribuída multa à entidade sindical em valor proporcional à sua condição econômica e à relevância do serviço público ou atividade estatal afetada."

${ }^{12}$ Conforme STOLL (2007, p. 69-70), "não podemos nos esquecer que o servidor público é um trabalhador, possuindo as mesmas necessidades individuais que o empregado do setor privado, no tocante à sua vida, necessidades de segurança, necessidades materiais, necessidades ligadas à realização pessoal, enfim, as necessidades normais de qualquer ser humano inserido no mercado de trabalho". 
o critério de subordinação jurídica pelo de dependência econômica, fato inequivocamente presente no âmbito do serviço público.

Também ROCHA (1999, p. 50-55) extrai da primazia constitucional atribuída ao valor social do trabalho, a possibilidade de valorização do servidor público, com a garantia de seus direitos fundamentais enquanto "trabalhador".

A partir da premissa de que o princípio da proteção também pode ser voltado ao servidor público abordaremos criticamente o tema da negociação coletiva no âmbito do serviço público e a situação atual da Convenção no 151, da OIT, no Direito brasileiro.

Segundo ROMITA (2009, p. 364), a omissão do art. 39,§ 2ํㅡ, da Constituição Federal em torno do direito à negociação coletiva no setor público não implica sua proibição. Até mesmo porque a negociação entre servidores públicos e Administração ocorre a todo tempo, forçada ou não por movimentos grevistas ${ }^{13}$. O ordenamento jurídico e sua interpretação não podem ser alheios aos fatos sociais, contrariando a própria realidade. Os acordos e convenções coletivos, elucida aquele autor, são apenas os instrumentos que formalizam o resultado bem sucedido da negociação (diálogo), encetando efeitos jurídicos palpáveis.

A ausência da convenção coletiva de trabalho no bojo do art. 39, § º da Constituição Federal, seria compreendida apenas porque para o setor público faz-se necessária a edição de lei, em sentido estrito, para a definição e modificação do regime jurídico estatutário (além das questões ligadas à exclusividade de iniciativa de lei e necessidade de previsão orçamentária), ao passo que a convenção coletiva de trabalho é, ela mesma, "meio de determinação conjunta de condições de trabalho", regulando relações entre os interessados e encontrando soluções para os problemas sociais e funcionais de ambas as partes (ROMITA, 2009, p. 365).

GARCIA (2010, p. 1284) expressa entendimento semelhante, indicando posição doutrinária "de acordo com a qual a negociação coletiva não pode ser excluída do setor público, mas deve ser adaptada às suas exigências. A negociação coletiva, nessa visão, é compatível com os preceitos da Administração Pública, mas deve resultar no encaminhamento de proposta legislativa, a ser aprovada pelos Poderes Legislativo e Executivo, de modo a atender ao princípio da legalidade".

Outrossim, a negociação coletiva não se resume às cláusulas econômicas (reajustamento salarial), incidindo em uma ampla gama de matérias: qualidade de vida no trabalho, saúde e segurança, mudanças tecnológicas, flexibilização do trabalho, não discriminação, participação nas decisões, etc. (ROMITA, 2009, p. 365).

A Convenção no 151, da OIT, portanto, não é incompatível com o setor público e o princípio da reserva legal não constitui óbice intransponível para a negociação coletiva; apenas há a ressalva de que os resultados dos procedimentos de negociação exigirão mediação

\footnotetext{
${ }^{13}$ STOLL (2007, p. 137-145) aponta diversos exemplos de processos permanentes de negociação coletiva envolvendo servidores públicos e o Estado: a Mesa Nacional de Negociação Permanente na Administração Pública Federal - MNNP, estabelecida em 16.06.2003, no âmbito da Administração Pública Federal, permitindo também mesas setoriais; o Sistema de Negociação Permanente para a Eficiência na Prestação dos Serviços Públicos Municipais de São Paulo - SINP e a Mesa Nacional de Negociação Permanente do Sistema Único de Saúde - MNNP-SUS, criada com a Resolução No 52, de 06.05.1993, do Conselho Nacional de Saúde.
} 
legislativa, não sendo, portanto, imediatamente vinculantes (ROMITA, 2009, p. 365-366; ROCHA, 1999, p. 353).

O negociado deve ser articulado em projeto de lei remetido ao Poder Legislativo através da autoridade competente. As cláusulas em relação às condições específicas de prestação da atividade da categoria podem ter, entretanto, vigência imediata (ROCHA, 1999, p. 355-356).

Um elemento que pode ser aprimorado, inclusive em relação às propostas de regulamentação da Convenção № 151 tratadas em tópico anterior, reside em conferir maior vinculatividade ao contéudo negociado, no momento em que a plataforma negociada é remetida ao Poder Legislativo, a fim de obter a necessária roupagem legal (observância do princípio da reserva legal e das regras orçamentárias).

O PLS 287/13, visto anteriormente, estabelece a necessidade de publicação dos termos da negociação no respectivo Diário Oficial, com detalhamento de seu conteúdo, e que os acordos firmados serão bilaterais, comprometendo as partes para seu cumprimento. Cremos, porém, e sem que isso possa ser interpretado como usurpação de competência legislativa, que se deva atribuir maior grau de vinculação entre os termos negociados e o conteúdo submetido à mediação legal.

A adoção de audiências públicas com ampla participação social e de setores técnicos do Governo (áreas jurídica, orçamentária e fazendária, por exemplo, além dos setores do funcionalismo com interesse no tema), seria apta a conferir maior grau de legitimidade a esse procedimento.

De outra parte, lembre-se que a previsão contida no art. 39, caput, da Constituição Federal de 1988 ("a União, os Estados, o Distrito Federal e os Municípios instituirão conselho de política de administração e remuneração de pessoal, integrado por servidores designados pelos respectivos poderes"), conforme redação dada pela Emenda Constitucional $n^{\circ} 19 / 98$, patenteia a opção constitucional pela condução da administração de pessoas no serviço público em bases negociadas com os próprios servidores (ROCHA, 1999, p. 353).

As dificuldades para a negociação envolvendo a Administração Pública, derivadas das amarras próprias da atividade administrativa (restrições à autocomposição, limites à negociação pela Administração Pública, pagamentos das dívidas através do sistema de precatórios, restrições orçamentárias, responsabilidade do gestor público, indisponibilidade do bem público e posição restritiva dos Tribunais de Contas quanto aos meios alternativos de resolução de disputas) não são intransponíveis.

Deve-se romper com o mito da indisponibilidade dos direitos tutelados pela Administração Pública. O que é indisponível é o interesse público, de titularidade da coletividade social como um todo, o qual não se confunde com o interesse ou posição de um determinado órgão ou entidade administrativa.

O interesse público ${ }^{14}$ não veda o reconhecimento de direitos legítimos. Não se deve confundir "indisponibilidade com intransigibilidade, pois esta somente se afigura nas situações em que a lei expressamente veda a transação", como é o caso da improbidade administrativa (SOUZA, 2014, p. 194).

\footnotetext{
${ }^{14}$ A própria ideia de interesse público, e sua verticalidade nas relações com a sociedade passa por intenso processo de revisão conceitual (HACHEM, 2011).
} 


\section{OBSERVAÇÕES CRÍTICAS SOBRE O CONFLITO ENTRE SERVIDORES PÚBLICOS E ADMINISTRAÇÃO PÚBLICA.}

A negociação coletiva é direito fundamental assegurado na Constituição Federal de 1988. Insere no âmbito laboral o conceito de diálogo social: o protagonismo concedido aos atores sociais assegura legitimidade e convivência harmônica entre estes - um ambiente consensual é redutor de conflitividade (ROMITA, 2009, p. 359).

O trabalho exercido no setor público está longe de ser a situação idealizada que muitos imaginam. Ao revés, trata-se de âmbito de trabalho bastante conflitivo, não somente em relação a questões salariais.

Também não se pode deixar de assinalar os inconvenientes da greve no serviço público. Diferentemente da greve ou toda sorte de movimento paredista no âmbito da iniciativa privada, onde geralmente apenas interesses privados são afrontados, a greve realizada no setor público não afeta os interesses de um "patrão", mas de toda a coletividade, que fica privada da prestação dos serviços e políticas públicas, como educação, saúde, serviços judiciários ou atividades de Previdência Social (sinalizando aqui os tipos mais frequentes de greve no serviço público).

Tudo isso demonstra e reforça a necessidade de se buscar a efetividade da implementação de mecanismos de negociação coletiva também no setor público, a começar da criação de uma cultura negocial entre representantes de servidores e mandatários da Administração Pública.

De outra parte, não se pode deixar de registrar que a negociação coletiva propriamente dita pode ser problemática em virtude da assimetria de poder entre as partes envolvidas, pois certos setores do funcionalismo possuem melhor nível de prestígio político e lobby do que outros, por isso são normalmente mais prestigiados em termos remuneratórios (BOTASSI, 2006, p. 97), como as carreiras ligadas à área econômica do Governo ou os setores policiais.

Também vislumbramos, no sindicalismo público, vicissitude encontrada no setor privado relativa à deficiência da representação sindical e alienação em relação às pretensões da categoria, frustrando a negociação coletiva (FREITAS JR., 1989, p. 17).

Outro fator contrário à ocorrência da efetiva negociação coletiva no setor público diz respeito ao atual momento político, não apenas nacional, onde prevalece a perspectiva de redução das atividades do Estado (plataforma neoliberal).

A negociação em torno da remuneração dos servidores públicos ou sobre seus direitos previdenciários consiste em importante decisão alocativa ${ }^{15}$. Entretanto, para que isso ocorra há

\footnotetext{
${ }^{15}$ FREITAS JR (2009, p. 518), compreende disputa alocativa como um problema alocativo incidente sobre bens tidos por escassos ou encargos tidos como necessários, sejam os bens e os encargos de natureza material ou imaterial, ao que se soma, no plano comportamental, consciente ou inconsciente, intencional ou não, contraposição no vetor de conduta entre dois ou mais sujeitos; por fím, no plano anímico ou
} 
necessidade de ambiente efetivamente democrático e que exista espaço para transigir em torno dos gastos públicos, sem que se fique refém do fundamentalismo fiscal atualmente prevalecente.

A primazia que se almeja para a negociação coletiva para resolução dos conflitos no âmbito do serviço público (mais exatamente na relação servidores-Estado) também pode ser justificada e compreendida à luz da perspectiva construtiva (e não destrutiva) do conflito: os conflitos podem ser considerados não como problemas, mas como oportunidades de crescimento (DEUTSCH, 1973). Se o conflito não pode ser evitado, inclusive por se constituir em elemento inerente às relações sociais, que ao menos seja considerado como janela de oportunidade para aprimoramento desse tipo de relação laboral e, indiretamente, do próprio serviço público.

A negociação coletiva no setor público, nesses termos, pode ensejar não apenas melhoria na condição salarial dos servidores públicos, mas também a criação de condições para melhor efetividade das políticas públicas, melhorando nível motivacional e comprometimento da categoria, com fortalecimento das instituições estatais.

\section{CONCLUSÕES}

Diversos elementos extraídos do ordenamento jurídico brasileiro expostos ao longo deste trabalho científico permitem entrever a plena possibilidade de aplicação do conteúdo da Convenção nํ 151, da OIT, para resolução negociada dos conflitos existentes no âmbito do serviço público, tornando injustificável a mora na sua regulamentação.

A única explicação possível para essa situação de mora jurídica reside na premissa do fundamentalismo fiscal e na perspectiva generalizada de desmonte/sucateamento das estruturas necessárias ao exercício efetivo das funções públicas.

Entretanto, conforme demonstrado acima, a negociação coletiva consiste em mecanismo muito mais adequado à resolução dos conflitos laborais no âmbito do setor público que a greve: mais democrático e legítimo, além de evitar os prejuízos laterais inerentes ao movimento paredista, como a paralisação das atividades essenciais à coletividade.

\section{REFERÊNCIAS}

BOTASSI, Carlos. Ensayos de Derecho Administrativo. La Plata: Libreria Editora Platense, 2006.

DEUTSCH, Morton. The resolution of conflict - constructive and destructive processes. New Haven: Yale University Press, 1973.

FREITAS JR., Antonio Rodrigues de. Cultura de justiça e limites da mediação para a difusão da cultura da paz, p. 509-532, in: SALLES, Carlos Alberto de (coord.). As grandes transformações do processo civil brasileiro. Homenagem ao professor Kazuo Watanabe. São Paulo: Quartier Latin, 2009.

motivacional, a disputa alocativa reúne em si sujeitos portadores de percepções diferentes sobre como tratar o problema alocativo, como função de valores de justiça. 
Direito do trabalho na era do desemprego:

instrumentos jurídicos em políticas públicas de fomento à ocupação. São Paulo: LTr, 1999.

Sindicato: domesticação e ruptura - um estudo da representação sindical no direito brasileiro. S. Paulo: Ordem dos Advogados do Brasil, Departamento Editorial, 1989.

GADAMER, Hans-Georg. Verdade e Método - traços fundamentais de uma hermenêutica filosófica, vol. I, 11ª ed., Petrópolis: Vozes, 2011.

GARCIA, Gustavo Filipe Barbosa. Curso de Direito do Trabalho, $4^{\mathrm{a}}$ ed., rev., atual. e ampliada. Rio de Janeiro: Forense, 2010.

HACHEM, Daniel Wunder. Princípio constitucional da supremacia do interesse público. Belo Horizonte: Fórum, 2011.

MATTOS, Mauro Roberto Gomes de. Administração, in MARTINS, Ives Gandra da Silva; MENDES, Gilmar Ferreira; NASCIMENTO, Carlos Valder do (coord.). Tratado de Direito Constitucional, vol. 1. S. Paulo: Saraiva, 2010.

NEIVA, Rogério. Direito e Processo do Trabalho aplicados à Administração Pública e Fazenda Pública. S. Paulo: Método, 2012.

ROCHA, Carmen Lúcia Antunes. Princípios constitucionais dos servidores públicos. São Paulo: Saraiva, 1999.

ROMITA, Arion Sayão. Direitos fundamentais nas relações de trabalho, $3^{a}$ ed., rev. e aumentada. São Paulo: LTr, 2009.

SOUTO MAIOR, Jorge Luiz. Curso de Direito do Trabalho, vol. I - parte I. São Paulo: LTr, 2011.

SOUZA, Luciane Moessa de. Resolução de conflitos envolvendo o Poder Público: caminhos para uma consensualidade responsável e eficaz. GABBAY, Daniela Monteiro; TAKAHASHI, Bruno (coord.). Justiça Federal: inovações nos mecanismos consensuais de solução de conflitos. Brasília: Gazeta Jurídica, 2014.

STANDING, Guy. O precariado - a nova classe perigosa. Belo Horizonte Autêntica, 2015.

STOLL, Luciana Bullamah. Negociação coletiva no setor público. São Paulo: LTr, 2007. 